\title{
Elimination of synaptonemal complex irregularities in a Lolium hybrid
}

\author{
G. Jenkins and \\ J. White
}

Department of Agricultural Sciences, University College of Wales, Penglais, Aberystwyth, Dyfed, SY23 3DD, U.K.

The diploid hybrid ryegrass, Lolium temulentum $\times$ L. perenne $(2 n=14)$, contains two sets of chromosomes which are structurally and genetically dissimilar. Whole-mount surface spreading of synaptonemal complexes from 35 pollen mother cell nuclei shows that chromosome pairing during meiotic prophase is highly irregular, with homoeologues and heterologues pairing together to form multivalents. These are eliminated, however, during meiotic prophase in favour of homoeologous bivalents. In addition, the length differential between homoeologous chromosomes is accommodated in a coordinated fashion and is absorbed into the structure of the synaptonemal complexes. The hybrid thus displays a remarkable capacity to eliminate synaptonemal complex irregularities and to produce homoeologous bivalents, which are functionally and morphologically almost indistinguishable from their homologous counterparts in the parents.

\section{INTRODUCTION}

The two haploid sets of chromosomes in the diploid hybrid ryegrass Lolium temulentum $\times L$. perenne $(2 n=14)$ are both structurally and genetically dissimilar (Hutchinson et al., 1979). Homoeologues regularly form bivalents at first metaphase of meiosis however, with chiasma frequencies similar to the parents (Rees and Jones, 1967). Three-dimensional reconstruction of synaptonemal complexes (SCs) from serial electron micrographs has already shown that this is achieved not by the exclusive pairing of homoeologues during zygotene, but rather by the elimination of multivalents involving non-homologous chromosomes (Jenkins, 1985a). Furthermore, the SCs were seen to have a remarkable capacity to absorb considerable length differences between lateral components of homoeologues without adversely affecting their integrity and effectiveness. The timing and coordination of these two processes could not be ascertained from the reconstruction study, since it was impracticable to analyse the relatively large number of cells required. In this study the technique of wholemount surface spreading of SCs was employed, which permitted analysis of a sufficient number of cells to specifically monitor the progress and kinetics of the elimination of synaptic irregularities.

\section{MATERIALS AND METHODS}

The material used in this study was the progeny of a test-cross between Lolium temulentum Ba3081 (Welsh Plant Breeding Station) and the second backcross generation of Lolium perenne Ba9436 (Welsh Plant Breeding Station) $\times$ LP19 (Taylor and Evans, 1977). The material was an integral part of a plant breeding project designed to transfer diploidising genes from Lp19 to agronomically more important Ba9436, with the ultimate objective of creating a chromosomally stable allotetraploid hybrid cultivar between $L$. perenne and $L$. multiflorum (Scanlon, 1988).

The plants were grown in 5 inch pots in an unheated greenhouse and meiotic inflorescences were sampled during April to June. Those destined for light microscopy were fixed in Carnoy's fixative. Mean bivalent, multivalent, and chiasma frequencies were scored from at least 20 pollen mother cells per plant using conventional acetocarmine squash methods.

The areas of chromosomes at first metaphase were measured from prints at $6000 \times$ magnification using a Bausch and Lomb Hipad digitiser connected to a BBC model B microcomputer.

Whole-mount surface spreads of SCs for electron microscopy were prepared according to the method detailed in White and Jenkins (1987), with 
the following modifications:

(1) Macerated anther material was left in digestion medium for $6 \mathrm{~min}$.

(2) The detergent solution was added to the cell suspension on the depression slide.

(3) After a spreading time of $10 \mathrm{~min}$ the suspension was washed down onto a plasticcoated slide using the fixative (6-7 drops).

\section{First metaphase}

All 45 plants scored in the test-cross progeny were diploid $(2 n=2 x=14)$, and had an overall mean chiasma frequency of 10.0 per cell, with a range of $7 \cdot 7$ to $12 \cdot 8$. The reduction and variation in chiasma frequencies, compared with the hybrid used in the previous study (Jenkins, 1985a), are attributable to the action and segregation of diploidising genes from Lp19. These suppress chiasmate association of homoeologues at this stage (Taylor and Evans, 1977). The chromosomes form distinctly heteromorphic bivalents (fig. 1), as homoeologues from the two parental sets of chromosomes differ in size by on average 50 per cent (Hutchinson et al., 1979).

In a randomly scored sample of 960 pollen mother cells at metaphase I, 29 (or 3 per cent of cells contained either one trivalent or one quadrivalent. These multivalents must inevitably involve non-homologous chromosomes, joined apparently by authentic chiasmata (fig. 1). It is not possible to state categorically whether these configurations are the result of heterozygosity for a simple translocation, or of chiasma formation between non-homologous segments of chromosomes, as the identity of the chromosomes cannot be determined from morphological criteria alone. However, if the former were true it would be expected that the same chromosomes would form multi. valents in different cells. In order to test this, 11 pollen mother cells at metaphase I were selected, in which the sites of all chiasmata could be seen and the area of each individual chromosome of the complement could be estimated. Table 1 shows the ranked areas of each chromosome, and indicates those which participate in multivalent formation. Even allowing for the errors inherent in estimating chromosome areas, and assuming that size is a reasonable gauge of identity, it can be

Figure 1 First metaphase in hybrid pollen mother cells showing: (a) typical heteromorphic rod and ring bivalents, and two univalents; (b) a single trivalent and univalent (arrows); (c) a quadrivalent (arrow). Bar equals $10 \mu \mathrm{m}$.
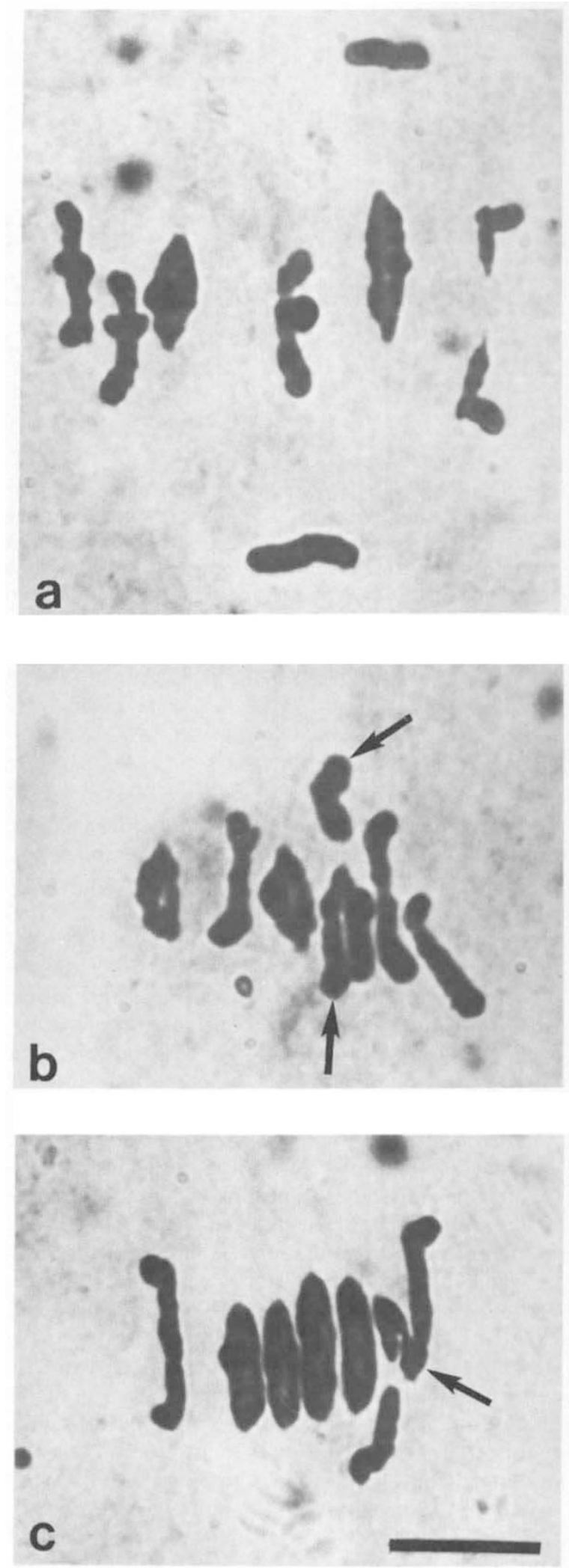
Table 1 Ranked areas (arbitrary units) of individual chromosomes in 11 metaphase I cells. Chromosomes involved in multivalents are marked with an asterisk $(*)$

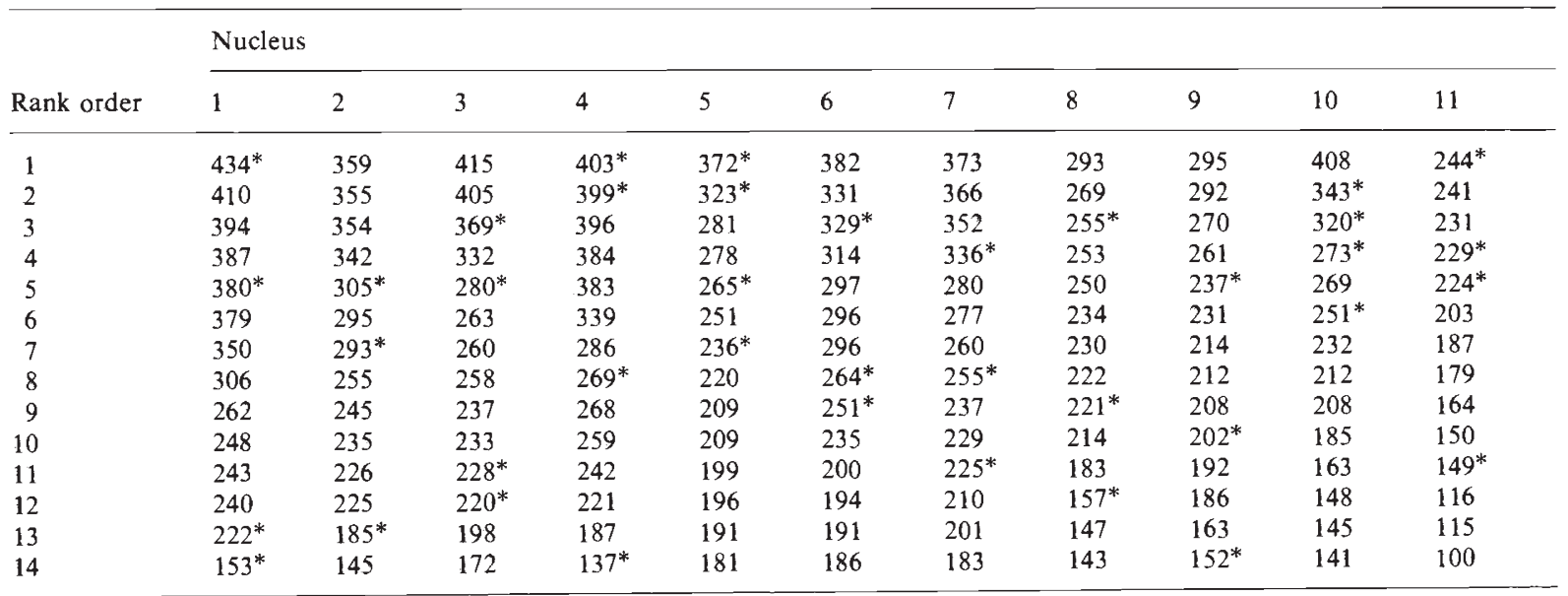

seen that there is no obvious propensity for chromosomes of certain sizes to form multivalents. In other words, it would seem likely that the multivalents are not the result of translocation involving the same four chromosomes, but rather the random chiasmate association of non-homologous chromosomes. Indeed, they may be the result of failure in the process which eliminates multivalents during meiotic prophase.

\section{Meiotic prophase}

Thirty-five cells from 15 plants were spread and stained to reveal complete complements of SCs (fig. 2). Each spread was analysed quantitatively with respect to the parameters shown in table 2 .

(a) Loops. The difference in size between homoeologues within bivalents is manifested at zygotene and pachytene by the formation of lateral component loops. These fold back upon themselves to form SCs which project perpendicularly from the main SC of the bivalent (fig. 3). In fact, they appear identical to those previously reported in a serial section reconstruction study of similar material (Jenkins, 1985a). They also comply with previous reports in that they are of variable numbers in cells of probably the same stage, and occupy interstitial regions of bivalents.

The analysis of a relatively large number of spread cells compared with the reconstruction study (Jenkins, 1985a) permitted a quantitative evaluation of the relationship between the number of loops and percentage pairing per cell. The regression shown in fig. 4 is highly significant $(P<$ 0.01 ; percentages transformed to angles).

(b) Accommodation. Fig. 5 shows the plot of the total percentage difference in length between lateral components of homoeologues against the overall percentage pairing of the cell. It was possible to calculate accurate length differences for only 18 of the 35 cells shown in table 2 . The regression is highly significant $(P<0.001 ;$ percentages transformed to angles).

(c) Multivalents. Examination of table 2 reveals that 23 ( 65 per cent) of the 35 spread cells analysed contain at least one (and up to three) multivalents (fig. 3), consisting of between three and fourteen chromosomes each. This contrasts sharply with observations at metaphase I, at which stage only three per cent of cells had either one trivalent or one quadrivalent.

The multiple associations are held together by substantial lengths of non-homologous SC, which occurs in both telomeric and interstitial segments of the chromosomes. It must, however, be largely ineffective in terms of crossing-over, since the vast majority of multivalents are eliminated in favour of bivalent formation before metaphase I.

The number of bivalents in a cell is inversely proportional to the number of chromosomes involved in multivalents, and has been used in fig. 6 as a convenient means of correlating this parameter with percentage pairing for 30 of the 35 cells in which the number of bivalents could be accurately determined. The regression is highly significant $(P<0.01$; percentages transformed to angles $)$. 
Table 2 Data from 35 spread zygotene cells, ranked in order of increasing percentage pairing. The lateral component length difference between the two genomes of the hybrid could be measured unambiguously in 18 cells only. The number of bivalents in five of the cells $\left(^{*}\right)$ was deduced from the number of multivalents and not measured directly, because of substantial breakage of the lateral components. For this reason these data were not included in the regression analysis depicted in fig. 6 . Each nucleus was scored for the number of univalents (I), bivalents (II), trivalents (III), quadrivalents (IV) and higher valences ( $>$ IV)

\begin{tabular}{|c|c|c|c|c|c|c|c|c|c|c|}
\hline \multirow{2}{*}{$\begin{array}{l}\text { Plant } \\
\text { no. }\end{array}$} & \multirow{2}{*}{$\begin{array}{l}\text { SC } \\
\text { length } \\
(\mu \mathrm{m})\end{array}$} & \multirow{2}{*}{$\begin{array}{l}\text { LC } \\
\text { length } \\
(\mu \mathrm{m})\end{array}$} & \multirow{2}{*}{$\begin{array}{l}\text { Pairing } \\
\text { (per cent) }\end{array}$} & \multirow{2}{*}{$\begin{array}{l}\text { Length } \\
\text { difference } \\
\text { (per cent) }\end{array}$} & \multicolumn{5}{|c|}{ No. of pairing configurations } & \multirow{2}{*}{$\begin{array}{l}\text { No. of } \\
\text { loops }\end{array}$} \\
\hline & & & & & I & II & III & IV & $>I V$ & \\
\hline 12 & $254 \cdot 5$ & $1321 \cdot 5$ & $38 \cdot 5$ & - & 1 & 3 & 1 & 1 & 0 & 0 \\
\hline 3 & $235 \cdot 8$ & $1201 \cdot 9$ & $39 \cdot 2$ & - & 0 & $2^{*}$ & 0 & 0 & 1 & 4 \\
\hline 5 & $331 \cdot 6$ & $1248 \cdot 4$ & $53 \cdot 1$ & $38 \cdot 8$ & 0 & 3 & 0 & 0 & 1 & 0 \\
\hline 1 & $250 \cdot 2$ & $938 \cdot 4$ & $53 \cdot 3$ & - & 0 & $5^{*}$ & 0 & 1 & 0 & 0 \\
\hline 1 & $244 \cdot 4$ & $878 \cdot 8$ & $55 \cdot 6$ & $34 \cdot 7$ & 0 & 4 & 0 & 0 & 1 & 3 \\
\hline 13 & $349 \cdot 3$ & $1219 \cdot 0$ & $57 \cdot 3$ & $38 \cdot 3$ & 0 & 3 & 0 & 2 & 0 & 1 \\
\hline 4 & $180 \cdot 8$ & $628 \cdot 8$ & $57 \cdot 5$ & - & 0 & $3^{*}$ & 0 & 2 & 0 & 3 \\
\hline 3 & $241 \cdot 2$ & $796 \cdot 8$ & $60 \cdot 5$ & - & 0 & 1 & 0 & 0 & 1 & 2 \\
\hline 15 & $265 \cdot 6$ & $849 \cdot 2$ & $62 \cdot 6$ & - & 2 & 4 & 0 & 1 & 0 & 6 \\
\hline 13 & $253 \cdot 2$ & $798 \cdot 4$ & $63 \cdot 4$ & - & 0 & 7 & 0 & 0 & 0 & 1 \\
\hline 1 & $204 \cdot 3$ & $642 \cdot 2$ & $63 \cdot 6$ & - & 0 & 7 & 0 & 0 & 0 & 4 \\
\hline 8 & $254 \cdot 8$ & $794 \cdot 8$ & $64 \cdot 1$ & - & 0 & $4^{*}$ & 0 & 0 & 1 & 1 \\
\hline 7 & $397 \cdot 6$ & $1236 \cdot 4$ & $64 \cdot 3$ & - & 0 & 1 & 0 & 3 & 0 & 4 \\
\hline 5 & $198 \cdot 8$ & $611 \cdot 3$ & $65 \cdot 0$ & $29 \cdot 4$ & 2 & 6 & 0 & 0 & 0 & 3 \\
\hline 15 & $265 \cdot 4$ & $766 \cdot 4$ & $69 \cdot 3$ & - & 2 & 4 & 0 & 1 & 0 & 4 \\
\hline 1 & $217 \cdot 6$ & 614.9 & $70 \cdot 8$ & - & 0 & 3 & 0 & 2 & 0 & 2 \\
\hline 3 & $450 \cdot 7$ & $1260 \cdot 1$ & $71 \cdot 5$ & - & 0 & 0 & 0 & 0 & 1 & 4 \\
\hline 10 & $398 \cdot 0$ & $1046 \cdot 8$ & $76 \cdot 0$ & - & 1 & $3^{*}$ & 1 & 1 & 0 & 3 \\
\hline 7 & 314.4 & $801 \cdot 2$ & $78 \cdot 5$ & $23 \cdot 1$ & 0 & 5 & 0 & 1 & 0 & 3 \\
\hline 7 & $364 \cdot 8$ & $914 \cdot 0$ & $79 \cdot 8$ & $13 \cdot 7$ & 0 & 5 & 0 & 1 & 0 & 7 \\
\hline 1 & $227 \cdot 7$ & $569 \cdot 8$ & $79 \cdot 9$ & $9 \cdot 8$ & 0 & 5 & 0 & 1 & 0 & 3 \\
\hline 5 & $374 \cdot 6$ & $904 \cdot 2$ & $82 \cdot 9$ & $18 \cdot 2$ & 2 & 6 & 0 & 0 & 0 & 2 \\
\hline 7 & $480 \cdot 8$ & $1139 \cdot 2$ & $84 \cdot 4$ & - & 0 & 0 & 1 & 0 & 1 & 7 \\
\hline 7 & $438 \cdot 6$ & $1030 \cdot 6$ & $85 \cdot 1$ & $11 \cdot 2$ & 0 & 7 & 0 & 0 & 0 & 5 \\
\hline 2 & $581 \cdot 0$ & $1341 \cdot 5$ & $86 \cdot 6$ & $9 \cdot 9$ & 0 & 5 & 0 & 1 & 0 & 2 \\
\hline 10 & 233.6 & $537 \cdot 2$ & $87 \cdot 0$ & - & 0 & 5 & 0 & 1 & 0 & 6 \\
\hline 6 & $325 \cdot 8$ & $742 \cdot 0$ & $87 \cdot 8$ & $17 \cdot 5$ & 0 & 7 & 0 & 0 & 0 & 4 \\
\hline 2 & $298 \cdot 8$ & $660 \cdot 2$ & $90 \cdot 5$ & $6 \cdot 4$ & 0 & 7 & 0 & 0 & 0 & 5 \\
\hline 9 & $402 \cdot 0$ & $886 \cdot 8$ & $90 \cdot 7$ & $5 \cdot 8$ & 0 & 7 & 0 & 0 & 0 & 4 \\
\hline 11 & $304 \cdot 6$ & $635 \cdot 6$ & $95 \cdot 8$ & $16 \cdot 2$ & 0 & 5 & 0 & 1 & 0 & 6 \\
\hline 14 & $431 \cdot 0$ & 896.4 & $96 \cdot 2$ & - & 0 & 3 & 0 & 2 & 0 & 5 \\
\hline 15 & $220 \cdot 5$ & 452.9 & $97 \cdot 4$ & $15 \cdot 5$ & 0 & 7 & 0 & 0 & 0 & 5 \\
\hline 11 & $373 \cdot 6$ & $766 \cdot 4$ & $97 \cdot 5$ & $13 \cdot 4$ & 0 & 7 & 0 & 0 & 0 & 6 \\
\hline 9 & $280 \cdot 4$ & $572 \cdot 0$ & 98.0 & $1 \cdot 4$ & 0 & 7 & 0 & 0 & 0 & 1 \\
\hline 1 & $303 \cdot 6$ & 616.4 & $98 \cdot 5$ & $7 \cdot 5$ & 0 & 7 & 0 & 0 & 0 & 5 \\
\hline
\end{tabular}

\section{DISCUSSION}

The hybrid between $L$. temulentum and L. perenne is presented during meiotic prophase with problems that would not be encountered by either of the parents. Firstly, hybridity appears to disrupt the control mechanism which prevents the synapsis of nonhomologous chromosomes during zygotene. Secondly, chromosomes of both genetic and structural dissimilarity need to be paired intimately and accurately in order to optimise chiasma frequencies and to ensure regular segregation of chromosomes. The results above show that this hybrid has a remarkable capacity for overcoming these difficulties by eliminating SC irregularities during meiotic prophase. The result, in most cases, is the efficient production of seven homoeologous bivalents per cell, each competent to form at least one chiasma. The question remains as to how and when the elimination of these irregularities actually takes place.

In the absence of a means of independently substaging zygotene and pachytene, the relationships depicted in figs 4,5 and 6 can be interpreted in one of two equally likely ways.

\section{Kinetics}

The first assumes that percentage pairing represents substage of zygotene and is, therefore, a gauge of time. If this were the case, fig. 4 would show that there is a significant linear increase in 


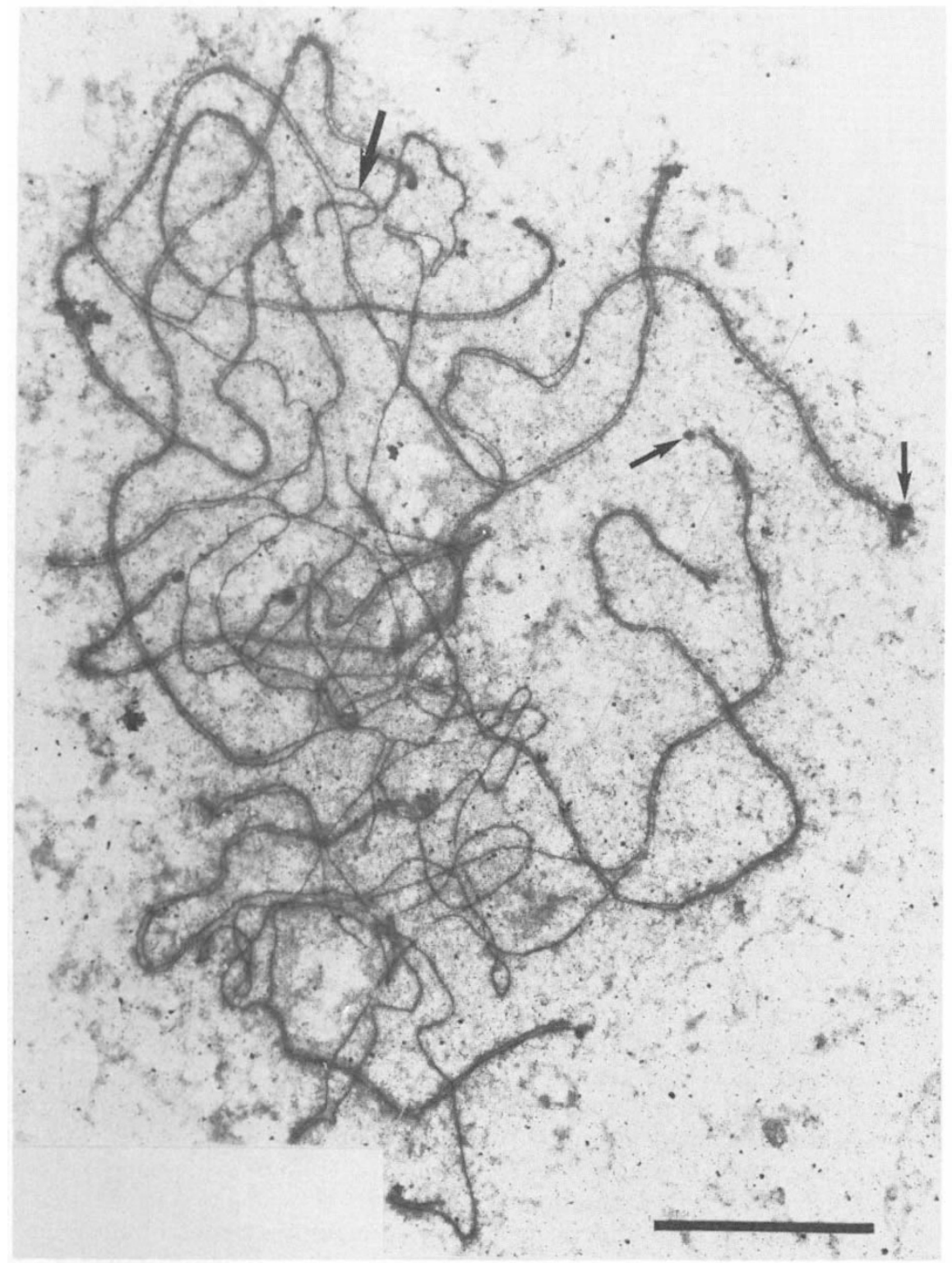

Figure 2 Electronmicrographic montage of a surface spread mid-zygotene nucleus. Note the presence of an unpaired interstitial loop (large arrow) and electron-dense telomeric features (small arrows). Bar equals $5 \mu \mathrm{m}$.

the number of loops as pairing progresses. This would not be perhaps unexpected, since loops are only likely to be formed following completion of the main $\mathrm{SC}$ axes in the regions adjacent to the loop. A kinetic interpretation could also be offered for the relationship shown in fig. 5. In other words, as pairing proceeds the difference in length between homoeologues is reduced. By extrapolation, it could be argued that the difference would be expected to be less than six per cent upon entry into pachytene at 100 per cent pairing. Accommodation of the length differential is very likely to disrupt the juxtaposition of homologous sequences, as demonstrated by the mismatching of centromeres, but seems to have surprisingly little effect on chiasma formation (Jenkins, 1985a). The process may continue throughout pachytene with a complete equalization of lateral component lengths. Such a process had been called synaptic adjustment, whereby a second round of SC forma- 


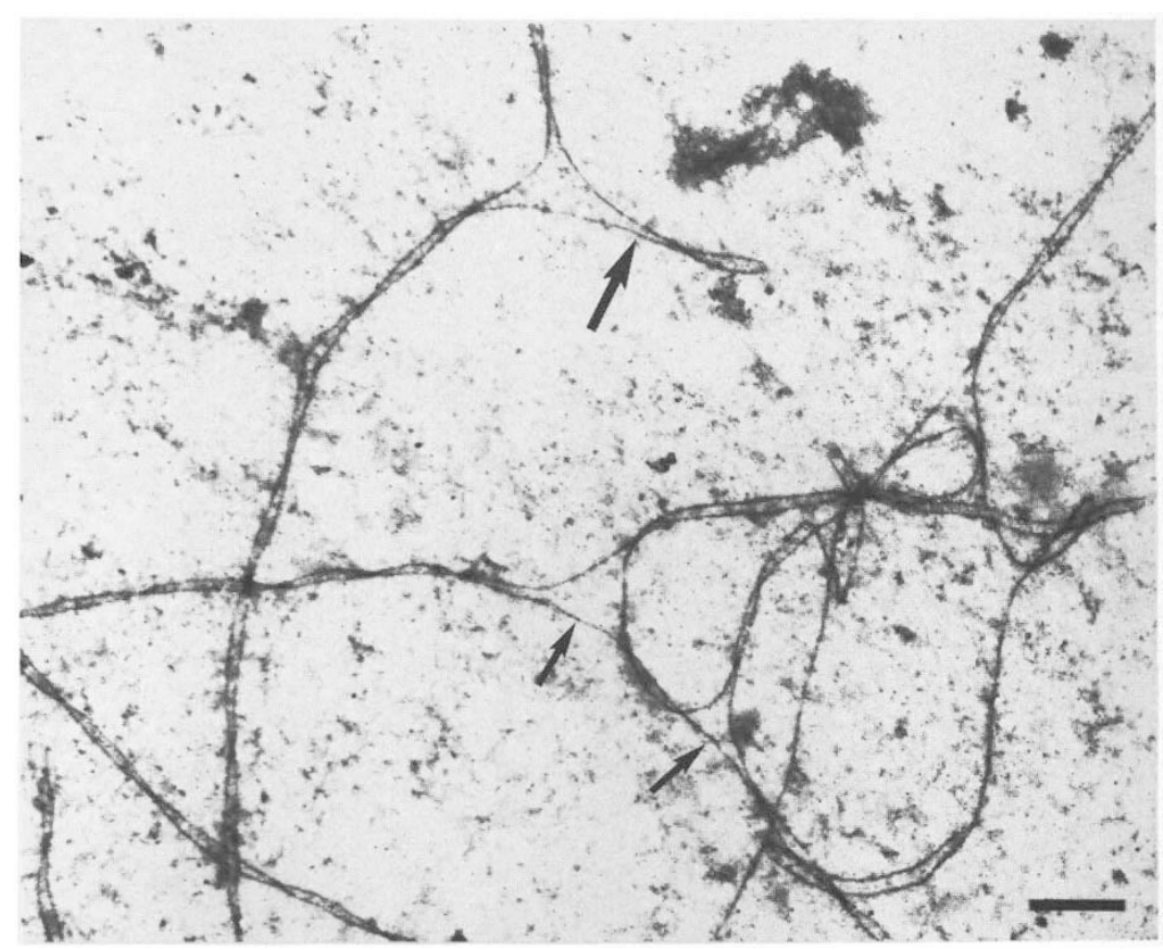

Figure 3 Electronmicrograph showing a foldback loop (large arrow) and exchanges of pairing partners (small arrows). Bar equals $1 \mu \mathrm{m}$.

tion during pachytene in male mice transforms duplications and inversion loops into straight SCs (Moses and Poorman, 1981; Moses et al., 1982).

Fig. 5 could also be interpreted in such a way that at zero per cent pairing there would be a difference in length of 72 per cent between homoeologous lateral components. This, however, presupposes that the relationship depicted in fig. 5 is linear also at low percentage pairing values, and that the average difference in DNA amounts of 50 per cent between homoeologues underestimates lateral component length differences. If, as would seem more likely, the initial length difference is about 50 per cent, the regression line in fig. 5 may actually plateau at that value, correlating with a pairing value of 33 per cent. In other words, it may be that when the chromosomes are about one third paired the accommodation mechanism is initiated. The delay in accommodation would be consistent with the observation that synapsis is initiated preferentially at the telomeres, at which sites there appears to be little length differential requiring adjustment (Jenkins, 1985a). The relatively high degree of homology at the telomeres may explain the lack of disruption of chiasmata, which form distally.
Fig. 6 could show that there is a linear increase in the number of bivalents as zygotene proceeds. It could, of course, be argued that this is entirely due to asynchronous pairing of univalents and accumulation of bivalents throughout zygotene. However, the data in table 2 show that even at early zygotene stages the majority of chromosomes are not as univalents but are involved in multivalents. A more satisfactory explanation is that the majority of bivalents are generated by the progressive transformation of multivalents and a second round of SC formation. According to this explanation a very low number of multivalents escapes the elimination process and survives to metaphase I.

If percentage pairing represents progress through zygotene, the data show that SC irregularities are subjected to a systematic and coordinated elimination process throughout zygotene. The mechanics of this process are summarised in diagrammatic form in fig. 7. The figure shows a quadrivalent at early zygotene comprising two homoeologous pairs of chromosomes, 1-1' and $2-2^{\prime}$. In this case, the chromosomes are paired only at the telomeres, but have the potential to pair interstitially. Inherent instability of multivalents (Jenkins et al., 1988) and the progressive formation 


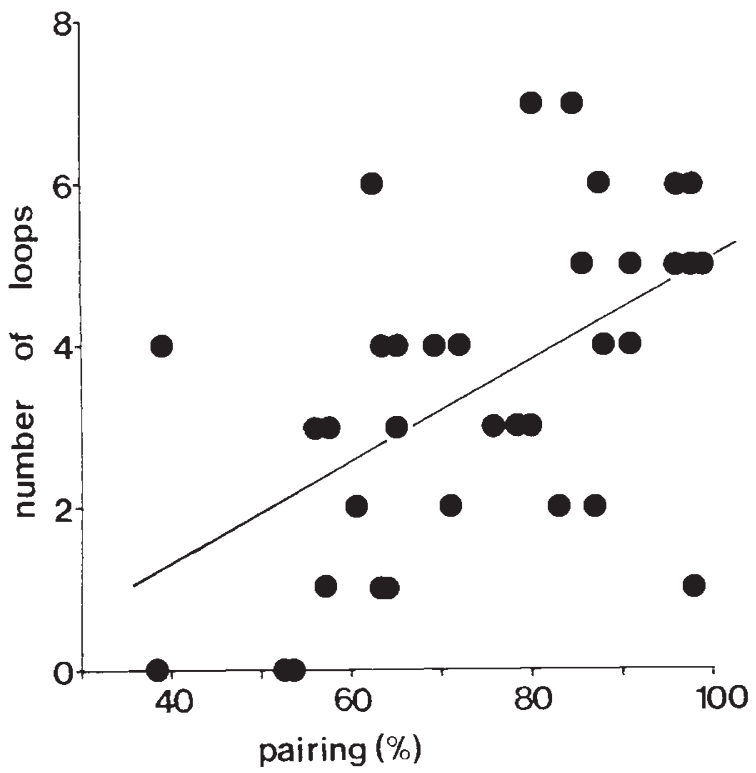

Figure 4 Plot of the total number of fold-back loops against percentage pairing for each of the 35 cells shown in table 2 . Loop number is a minimum estimate, as unpaired regions showing a pronounced length differential and a potential to form a fold-back were not included in the totals for each cell. Percentage pairing was calculated as the total length of lateral components involved in SC formation divided by the total length of lateral components of the cell, and multipied by 100 . The regression is highly significant $(P<$ $0 \cdot 01$ ).

of SCs from homoeologously paired telomeres only, may initiate and drive the elimination process. Telomeres released from nonhomologous association would be involved in a second round of homoeologous SC formation before interstitial synapsis is complete. If this were not so terminal overlaps would almost certainly be observed (Jenkins, 1985a). Accommodation would be expected to proceed as legitimate SCs are formed. Loop position would be dependent on the sites of initiation and progress of SC formation (Jenkins, 1988). By late zygotene, and before crossing-over, bivalents would be produced by reconstitution of SCs which are largely devoid of synaptic irregularity, and are functionally and morphologically almost indistinguishable from their homologous counterparts.

\section{Maximal pairing}

The second interpretation supposes that some of the variation in percentage pairing may represent different maximum extents of pairing. According to this interpretation, variation in percentage pairing does not necessarily give a reliable indication

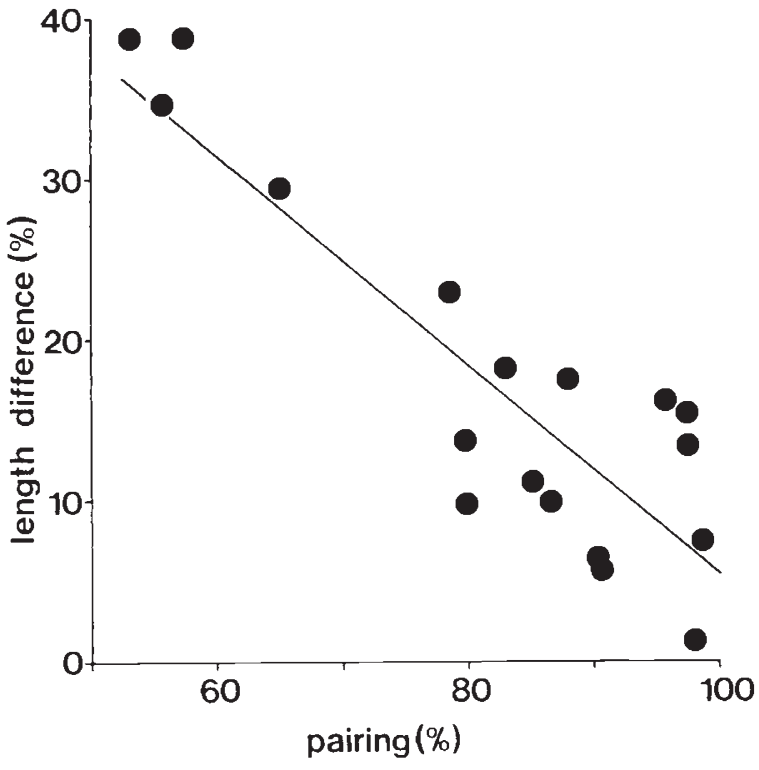

Figure 5 Plot of the percentage difference in total length between homoeologous lateral components against percentage pairing for 18 of the 35 cells shown in table 2 . It is assumed that bivalents are composed of homoeologous chromosomes, as are those pairs of chromosomes within multivalents which form the greatest lengths of SC between themselves. Percentage difference is calculated as the difference in total length between the two genomes divided by the smaller value, multiplied by 100 . The regression is highly significant $(P<0 \cdot 001)$.

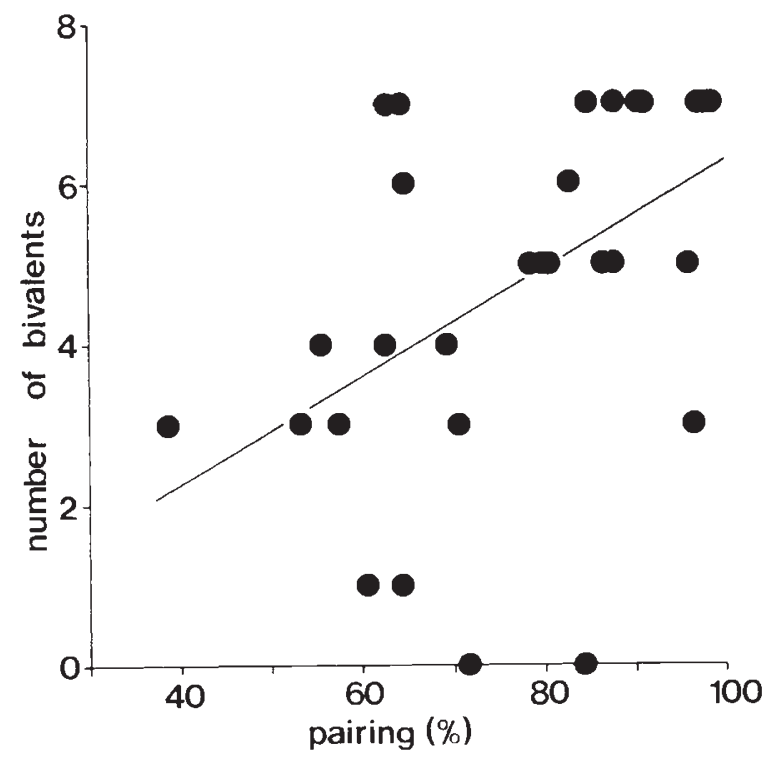

Figure 6 Plot of the number of bivalents against percentage pairing for 30 of the 35 cells shown in table 2 . The regression is highly significant $(P<0.01)$ and shows that multivalents are systematically eliminated during zygotene. 


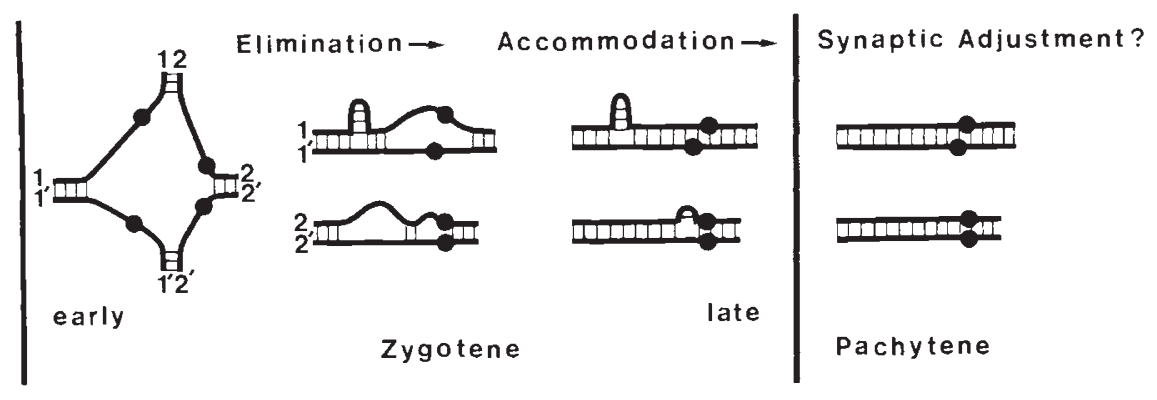

Figure 7 Schematic diagram showing how the concerted processes of elimination, accommodation and synaptic adjustment may systematically eliminate SC irregularities during meiotic prophase in the hybrid. Lateral components are represented by lines, $\mathrm{SC}$ by crosshatching, and centromeres by filled circles.

of meiotic stage. Failure to complete pairing is a likely alternative given the hybrid nature of the plant material and the fact that diploidising genes segregating in this population have been shown to have an inhibitory effect on SC formation at late pachytene in other diploid Lolium hybrids and their amphidiploids (Jenkins and Scanlon, 1987; Jenkins, 1986). A similar effect was also noted in wheat, when the dosage of analogous genes at the $\mathrm{Ph}$ locus was altered (Holm and Wang, 1988). If this interpretation were correct, the relationship depicted in fig. 6 would indicate that multivalents either cause or result in a reduction in the extent of pairing. The high chiasma frequencies and lack of multivalents at metaphase I could be explained in this case by crossing over and chiasma formation only in regions which are strictly homoeologously paired. Multivalents would be eliminated not during zygotene as in (1) above, but upon entry into diplotene (Jenkins, 1988).

It must be stressed that the two interpretations of the data are not necessarily mutually exclusive and both could generate the same chiasmate associations at metaphase I. Indeed, the actual mechanism of bivalent formation by/elimination of multivalents may lie somewhere in between.

Table 3 Species and hybrids showing fewer multivalents at metaphase I than during meiotic prophase

\begin{tabular}{|c|c|c|c|}
\hline & Family & Ploidy & Publications \\
\hline \multicolumn{4}{|l|}{ Species } \\
\hline Bombyx mori & Bombycidae & $3 \times, 4 \times$ & $\begin{array}{l}\text { Rasmussen 1977, 1987, } \\
\text { Rasmussen and Holm } 1979 .\end{array}$ \\
\hline Festuca arundinacea & Gramineae & $6 \times$ & Davies (unpublished) \\
\hline Triticum aestivum & Gramineae & $3 \times, 6 \times$ & $\begin{array}{l}\text { Hobolth 1981, Jenkins 1983, Wischmann 1986, Holm } 1986 \text {, } \\
1988 a, 1988 b \text {, Wang } 1988 \text {, Holm and Wang } 1988 .\end{array}$ \\
\hline Allium vineale & Liliaceae & $4 \times$ & Loidl 1986. \\
\hline Scilla autumnalis & Liliaceae & $3 \times, 4 \times$ & White et al. 1988, Jenkins et al. 1988. \\
\hline \multicolumn{4}{|l|}{ Hybrids } \\
\hline$\times H$. grandiflora & Compositae & $2 \times$ & See and Parker (unpublished) \\
\hline \multicolumn{4}{|l|}{ Lolium temulentum } \\
\hline$\times$ L. perenne & Gramineae & $2 \times, 3 \times, 4 \times$ & Jenkins $1985 a, 1985 b, 1986$. \\
\hline \multicolumn{4}{|l|}{ Triticum aestivum } \\
\hline$\times T$. kotschyi & Gramineae & $5 \times$ & Gillies 1987. \\
\hline \multicolumn{4}{|l|}{ Triticum aestivum } \\
\hline$\times$ Secale cereale & Gramineae & $4 \times$ & Abirached-Darmency et al. 1984, Wang and Holm 1988. \\
\hline \multicolumn{4}{|r|}{ 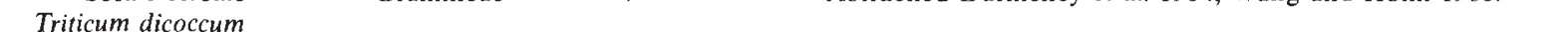 } \\
\hline$\times$ Secale cereale & Gramineae & $3 \times$ & Abirached-Darmency et al. 1984. \\
\hline
\end{tabular}


Elimination of multivalents during meiotic prophase is not a feature unique to this particular hybrid. It has been observed in other interspecific and intergeneric hybrids, and appears to be the means of exclusive bivalent formation in a wide range of polyploid species (table 3 ). Detailed examination of meiotic prophase in other hybrids and polyploids should reveal whether or not this phenomenon is widespread.

Acknowledgements The authors wish to thank G. M. Evans and M. J. Scanlon for the plant material used in this study. G. Jenkins acknowledges receipt of a Royal Society University Research Fellowship and J. White the receipt of an SERC grant (No. GR/D/42467).

\section{REFERENCES}

ABIRACHED-DARMENCY, M., CAUDERON, Y. AND ZICKLER, D. 1984. Meiotic chromosome pairing in three F1 (TriticumSecale) hybrids: A comparitive approach in light microscopy and electron microscopy. Biol. Cell, 51 (3), 365-372.

GilliEs, C. B. 1987. The effect of $\mathrm{Ph}$ gene alleles on synaptonemal complex formation in Triticum aestivum $\times T$. kotschyi hybrids. Theor. Appl. Genet., 74, 430-438.

Gillies, C. B., KUSPIRA, J. AND BHAMBHANI, R. N. 1987. Genetic and cytogenetic analyses of the $A$ genome of Triticum monococcum. IV. Synaptonemal complex formation in autotetraploids. Genome, 29, 309-318.

HOBOLTH, P. 1981. Chromosome pairing in allohexaploid wheat var. Chinese Spring. Transformation of multivalents into bivalents, a mechanism for exclusive bivalent formation. Carlsberg Res. Commun., 46, 129-173.

HOLM, P. B. 1986. Chromosome pairing and chiasma formation in allohexaploid wheat, Triticum aestivum analysed by spreading of meiotic nuclei. Carlsberg Res. Commun., 51, 239-294.

HOLM, P. B. 1988a. Chromosome pairing and synaptonemal complex formation in hexaploid wheat, monosomic for chromosome 5B. Carlsberg Res. Commun., 53, 57-89.

HOLM, P. B. 1988 b. Chromosome pairing and synaptonemal complex formation in hexaploid wheat, monoisosomic and diisosomic for the long arm of chromosome 5B. Carlsberg Res. Commun., 53, 111-113.

HOLM, P. B. AND WANG, X. 1988. The effect of chromosome $5 \mathrm{~B}$ on synapsis and chiasma formation in wheat, Triticum aestivum cv. Chinese Spring. Carlsberg Res. Commun., 53, 191-208.

HUTCHINSON, J., REES, H. AND SEAL, A. G. 1979. An assay of the activity of supplementary DNA in Lolium. Heredity, 43, 411-421.

JENKINS, G. 1983. Chromosome pairing in Triticum aestivum cv. Chinese Spring. Carlsberg Res. Commun., 48, 255-283.

JENKINS, G. 1985a. Synaptonemal complex formation in hybrids of Lolium temulentum $\times L$. perenne (L.). I. High chiasma frequency diploid. Chromosoma, 92, 81-88.
JENKINS, G. 1985b. Synaptonemal complex formation in hybrids of Lolium temulentum $\times L$. perenne (L.). II. Triploid. Chromosoma, 92, 387-390.

JENKINS, G. 1986. Synaptonemal complex formation in hybrids of Lolium temulentum $\times$ L. perenne (L). III. Tetraploid. Chromosoma, 93, 413-419.

JENKINS, G. 1988. Chromosome pairing in Lolium hybrids. In Brandham, P. E. (ed.) Kew Chromosome Conference III, HMSO, pp. 261-267.

JENKINS, G. AND REES, H. 1983. Synaptonemal complex formation in a Festuca hybrid in Brandham, P. E. and Bennett, M. D. (eds) Kew Chromosome Conference II, Allen and Unwin, London, pp. 233-242.

JENKINS, G. AND SCANLON, M. J. 1987. Chromosome pairing in a Lolium temulentum $\times L$. perenne diploid hybrid with a low chiasma frequency. Theor. Appl. Genet., 73, 516-522.

JENKINS, G., WHITE, J. AND PARKER, J. S. 1988. Elimination of multivalents during meiotic prophase in Scilla autumnalis. II. Tetraploid. Genome, 30, 940-946.

LOIDL, J. 1986. Synaptonemal complex spreading in Allium. II. Tetraploid A. vineale. Can. J. Genet. Cytol, 28, 754-761.

MOSES, M. J. AND POORMAN, P. A. 1981. Synaptonemal complex analysis of mouse chromosomal rearrangements. II. Synaptic adjustment in a tandem duplication. Chromosoma, 81, 519-535.

MOSES, M. J., POORMAN, P. A., RODERICK, T. H. AND DAVISSON, M. T. 1982. Synaptonemal complex analysis of mouse chromosomal rearrangements. IV. Synapsis and synaptic adjustment in two paracentric inversions. Chromosoma, 84, 457-474.

RASMUSSEN, S. W. 1977. Chromosome pairing in triploid females of Bombyx mori analysed by three-dimensional reconstructions of synaptonemal complexes. Carlsberg Res. Commun., 42, 163-197.

RASMUSSEN, S. W. 1987. Chromosome pairing in autotetraploid Bombyx males. Inhibition of multivalent correction by crossing over. Carlberg Res. Commun., 52 (3), 211-242.

RASMUSSEN, S. W. AND HOLM, P. B. 1979. Chromosome pairing in autotetrapoid Bombyx females. Mechanism for exclusive bivalent formation. Carlsberg Res. Commun., 44, 101-125.

REES, H AND JONES, G. H. 1967. Chromosome evolution in Lolium. Heredity, 22, 1-18.

SCANLON, M. J. 1988. The manipulation of diploidizing genes in Lolium. Ph.D. Thesis, University of Wales.

TAYLOR, I. B. AND EVANS, G. M. 1977. The genotypic control of homoeologous chromosome association in Lolium temulentum $\times$ L. perenne interspecific hybrids. Chromosoma, 62, 57-67.

WANG, X. 1988. Chromosome pairing analysis in haploid wheat by spreading of meiotic nuclei. Carlsberg Res. Commun., $53,135-166$.

WANG, X, AND HOLM, P. B. 1988. Chromosome pairing and synaptonemal complex formtion in wheat-rye hybrids. Carlsberg Res. Commun., 53, 167-190.

WHITE, J. AND JENKINS, G. 1987. Light and electron microscopy of the chromosomes of Hyacinthoides non-scripta (L.) Chouard ex Rothm. Caryologia, 40, 157-166.

WHITE, J., JENKINS, G. AND PARKER, J. S. 1988. Elimination of multivalents during meiotic prophase in Scilla autumnalis I. Diploid and triploid. Genome, 30, 930-939.

WISCHMANN, B. 1986. Chromosome pairing and chiasma formation in wheat plants triisosomic for the long arm of chromosome 5B. Carlsberg Res. Commun., 51, 1-25. 